\title{
Estructura política, redes político-clientelares y oscilaciones electorales en la Ciudad de México
}

\author{
Héctor Tejera, ${ }^{*}$ Diana Castańeda* ${ }^{* *}$
}

Perfiles Latinoamericanos, 25(50)

2017 | pp. $227-246$

DOI: $10.18504 / \mathrm{pl} 2550-011-2017$

\begin{abstract}
Resumen
El predominio del PRD como partido gobernante en la Ciudad de México ha favorecido la consolidación de una élite política asociada a diversas facciones partidarias, que sustenta su influencia en una estructura política de dominio territorial basada en redes político-clientelares. Enlazando la observación participante y las entrevistas en profundidad, el análisis de conglomerados georreferenciados de comportamiento electoral, y la comparación entre estudios de casos, se presentan los efectos de la acción de estas redes en el ámbito electoral. Todo ello se demuestra con el estudio de los conflictos electorales en dos delegaciones políticas de la ciudad mencionada.
\end{abstract}

\begin{abstract}
The supremacy of the PRD as the ruling party in Mexico City has led the consolidation of a political elite associated to different party factions. This elite supports its influence in a political structure of control, based in patronage networks. Linking participant observation and in-depth interviews, analysis of georeferenced clusters of electoral behavior, and comparison between case studies, the article shows the effects of the action of these networks in the electoral field; demonstrating all the above by studying the electoral conflicts in two political delegations in the aforementioned city.
\end{abstract}

Palabras clave: clientelismo, redes políticas, partidos políticos, Ciudad de México, elecciones, Iztapalapa, Cuajimalpa.

Keywords: Clientelism, political networks, political parties, City of Mexico, elections, Iztapalapa, Cuajimalpa.

* Doctor en Antropología Social por la Universidad Iberoamericana. Profesor-investigador, Universidad Autónoma Metropolitana, Unidad Iztapalapa | htejera@gmail.com

** Maestra en Sociología Política por el Instituto de Investigaciones Dr. José María Luis Mora. Investigadora en el Instituto de Estadística y Geografía (INEGI) | alejandria.cp@gmail.com 


\section{Introducción}

E

ste artículo presenta una propuesta de los factores que han permitido la consolidación de la estructura política que caracteriza actualmente a la Ciudad de México, ${ }^{1}$ así como de la forma en que esa estructura influye en las elecciones locales. Esto se realiza con base en un estudio comparativo de los procesos político-electorales en dos delegaciones políticas: Iztapalapa y Cuajimalpa. El propósito general del artículo es responder una interrogante: ¡̇se ha consolidado en los últimos quince años - periodo caracterizado por el triunfo electoral del Partido de la Revolución democrática (PRD) — una nueva estructura política en la Ciudad de México, la cual puede modificar los resultados de las elecciones en los procesos locales (delegacionales)? Al respecto entendemos estructura política como la forma en que se establecen las relaciones políticas, mismas que definen la manera de ejercer el poder en una sociedad y se encuentran configuradas por un contexto institucional, normativo y cultural.

En la primera parte del artículo se exponen brevemente los factores que han propiciado la formación de dicha estructura; en la segunda, se muestra cómo ella favorece prácticas políticas similares en delegaciones con características sociodemográficas distintas; en la tercera, se elabora una reflexión general sobre la relación entre esas prácticas políticas, la estructura política prevaleciente en la Ciudad de México, y el futuro del PRD.

Hemos estudiado la capital del país debido a que, como precisa Alvarado (2012) al caracterizarla, en ella se concentran los procesos políticos, económicos y sociales de mayor complejidad en México; aquí conviven las administraciones local y federal y, desde 1997, gobierna, bajo la bandera de la izquierda, un partido distinto al Partido Revolucionario Institucional (PRI). Además, se ha formado una nueva élite política que, siguiendo a Salas-Porras \& Luna (2012: p. 14), es un grupo de personas cuya influencia en el ámbito público y privado puede organizar lo social. En este artículo abordamos a ese grupo social integrado por líderes, funcionarios y legisladores perredistas que, en su quehacer como actores políticos, han adquirido la capacidad de perfilar el contexto en que se desenvuelve la vida de muchos habitantes de la ciudad, al legislar e implantar políticas públicas y, en el caso que nos ocupa, a definir elecciones.

Esta investigación se sustenta en una perspectiva etnográfica (Balbi \& Boivin, 2008) cuyo propósito ha sido observar en su densidad (Geertz, 1973) las prácticas de la política, qué significan para los involucrados (Auyero \& Joseph,

1 Con Ciudad de México nos referirnos a la mancha urbana que se ubica en el territorio del antiguo Distrito Federal, tal y como lo hace Álvarez (2013 [1998]). 
2007; Baczko, 1991), y sus resultados sociopolíticos. Se ha hecho observación sistemática del comportamiento político de actores clave (candidatos, funcionarios delegacionales y líderes de redes político-clientelares); ${ }^{2}$ así como entrevistas minuciosas a dichos actores bajo el compromiso del anonimato. ${ }^{3} \mathrm{La}$ certeza significativa de los resultados presentados se sustenta en la saturación etnográfica, es decir, en su confirmación mediante la redundancia o en la confrontación con información obtenida en situaciones similares (Creswell, 2007).

También se han utilizado estrategias cuantitativas, en particular el análisis histórico-estadístico organizado por clústeres (conglomerados) de resultados electorales locales a nivel de sección electoral. Esta información se ha correlacionado con los datos etnográficos a fin de explicar los efectos político-electorales del comportamiento de las redes en las delegaciones políticas. Se presentan dos tipos de mapas: el primero muestra clústeres basados en resultados electorales en las delegaciones analizadas e incluye cuadros que precisan la media estadística de la votación obtenida por los diferentes partidos en cada clúster, la desviación estándar de dicha media con relación al centro estadístico del clúster, y el número de secciones en cada uno de ellos. El segundo tipo de mapa muestra secciones electorales agrupadas en clústeres, vinculadas a distintos niveles de bienestar con base en el índice de desarrollo social (IDS) y el desempeño partidario-electoral histórico. ${ }^{4}$

La presente investigación abarca el periodo 2009-2012 y a diversas delegaciones políticas de la Ciudad de México. En ella han participado varios grupos de estudiantes e investigadores de los procesos políticos en el marco del proyecto interinstitucional de Ciencia Básica Conacyt "Las paradojas de la democracia en México".

\section{La configuración de la estructura política de la Ciudad de México}

La formación de la estructura política actual de la Ciudad de México ha sido impulsada tanto por la profundización de la democracia en el país, como por el predominio electoral del PRD a partir de 1997, el cual ha encontrado principal soporte en tres factores: en primer lugar, la tradición opositora manifestada electoralmente en la ciudad desde la década de los sesenta, probablemente im-

2 Entendemos redes politico-clientelares como las organizaciones sociales con capacidad para influir electoralmente en territorios específicos, y que a cambio de su apoyo político reciben bienes o servicios mediante la intermediación de sus líderes ante el gobierno o los partidos políticos.

3 Como lo establecen los códigos de ética del Colegio Mexicano de Antropología (1978) y la Asociación de Antropología Americana (1998).

4 Agradecemos el apoyo de los doctores Jaime Ramírez y Emelina Nava del Centro de Sistemas de Información Geográfica de El Colegio de México para la elaboración de los mapas referidos. 
pulsada por su desarrollo educativo, cultural y económico (Emmerich, 2005), y por las influencias culturales promovidas por la presencia de significativos grupos de intelectuales y organizaciones gremiales que desde la década de 1940 asumieron una postura crítica hacia el sistema político (Vaughan, 2001). En la década de 1960 , un promedio de $20 \%$ del sufragio capitalino fue para el Partido Acción Nacional (Pan) y un poco más de 9\% para el Partido Comunista Mexicano (РСM) (Gómez-Tagle, 2000: p. 39). Además, por entonces la ciudad mostraba el mayor índice de abstención electoral en el país (Becerra, 2005). Esta tradición puede haberse alimentado de los efectos políticos de los movimientos magisterial, estudiantil y cívico de los cincuenta y los sesenta; y de la crisis económica de inicios de los ochenta y la demanda de vivienda a raíz del sismo de 1985. Sucesos posteriores como el movimiento estudiantil de 1987, el electoral de 1988, el magisterial de 1989 (Álvarez, 2006) y la crisis económica y política iniciada en 1994, pueden haberla fortalecido.

Desde 1988, con la candidatura de Cuauhtémoc Cárdenas a la Presidencia de la República, los capitalinos han sufragado preferentemente por la izquierda. Sin embargo, las elecciones del ańo 2000 muestran que también es importante la tradición de oposición, la cual puede manifestarse más allá de las zonas que reiteradamente se inclinan por el PAN. ${ }^{5}$

El segundo factor es la interacción entre un reiterado apoyo electoral ciudadano al PRD desde 1997 (con excepción, insistimos, del año 2000), y las características internas de organización de ese partido. Antes de 1997 el PRD local era débil, pero luego las organizaciones urbanas existentes (muchas de ellas pertenecientes al Movimiento Urbano Popular) se le integraron durante la campaña electoral de Cárdenas para jefe de Gobierno; esto garantizaría a los líderes perredistas candidaturas a diputaciones locales y federales, y puestos en la estructura gubernamental a cambio de su apoyo durante los comicios. A partir de ese momento votar por el PRD fortalece política y electoralmente a los líderes de dichas organizaciones (Frutos, 2002; Bruhn, 2012: p. 140) y debilita a los integrantes que no tienen acceso a dichas redes, así sucedió con los intelectuales y los dirigentes históricos de la izquierda.

El tercer factor que configura la estructura política — evidenciado por la etnografía realizada - es la competencia de las facciones en el ámbito territorial e intrapartidario para consolidarse en las elecciones internas del PRD. Al incrementarse la importancia de los puestos internos del partido — pues por su medio se definen candidaturas y se influye en la designación de los que ocuparán cargos gubernamentales_- la querella entre facciones se exacerba y las elecciones me-

5 Recuérdese, por ejemplo, que en esas elecciones el candidato perredista a la Jefatura de Gobierno ganó por menos del uno por ciento de los votos al panista. 
diante votaciones abiertas (ya sean de militantes registrados o entre la población en general) impulsa el clientelismo, porque este sostiene grupos de apoyo que votarán en las elecciones internas. Además, las facciones rivales acuden a sus allegados ubicados en puestos gubernamentales para que los recursos públicos que ellos administran alimenten redes político-clientelares. ${ }^{6}$

En síntesis, pueden señalarse tres momentos en la formación de la estructura política predominante en la Ciudad de México: $a$ ) adhesión al PRD capitalino de los líderes e integrantes del movimiento urbano-popular; b) paulatina exclusión de la estructura partidaria de los dirigentes históricos y los intelectuales del perredismo nacional y el capitalino, y la disputa entre diferentes facciones por controlar dicha estructura y asegurar su preponderancia político-territorial; c) consolidación organizacional, política y económica de los grupos sobre espacios territoriales, cuya expansión depende del afianzamiento de sus redes político-clientelares, así como de negociaciones con otras fuerzas políticas con influencia en la Ciudad de México.

\section{Funcionamiento de la estructura política en la Ciudad de México: las redes político-electorales en el ámbito delegacional}

Demostrar cómo funciona la estructura política no es fácil, debido a que el predominio electoral del PRD permea en los procesos políticos que tras bambalinas delinean los resultados de los comicios. No obstante, el comportamiento electoral mostrado por Iztapalapa en 2009, y el de Cuajimalpa de 2012, evidenciaron el carácter de las negociaciones entre diversas facciones para la elección de candidatos, y en el ámbito territorial, el papel de las redes políticas tanto en las negociaciones referidas como en la definición de los resultados electorales.

Los casos de Iztapalapa y Cuajimalpa, no obstante sus diferencias, permiten mostrar que existen similitudes en el funcionamiento de la estructura política, destacándose las siguientes: a) ambas delegaciones han vivido alternancia política durante los últimos seis años. En Iztapalapa, durante las elecciones de 2009 triunfó el Partido del Trabajo (PT), y en Cuajimalpa, en 2012, ganó el PRI; b) los partidos ganadores en esas elecciones usualmente tienen bajos niveles de votación en la Ciudad de México; ${ }^{7}$ ) los aspirantes con mayor popularidad política entre la

6 Siguiendo a Belloni \& Beller (1996: p. 535), entendemos las facciones como grupos relativamente organizados con presencia en el marco de otro grupo más amplio, con el cual compiten para incrementar su poder.

7 Por ejemplo, un total de votos en la Ciudad de México de 11.23\%, mientras que en 2012, no obstante el carácter concurrente de dichas elecciones y el triunfo electoral del candidato a la presidencia, el PRI obtuvo $16.28 \%$. 
población no fueron designados como candidatos del PRD debido a pugnas (Iztapalapa) o negociaciones (Cuajimalpa) entre diferentes facciones de ese partido; d) los aspirantes basaron su posibilidad de obtener la jefatura delegacional vinculándose con otro (en Cuajimalpa, integrándose al PRI, y en Iztapalapa mediante una representación informal en el PT); ${ }^{8} e$ ) las redes con las cuales los aspirantes negociaron apoyo y puestos delegacionales impulsaron su triunfo electoral; $f$ ) en ambas delegaciones la identificación política entre los integrantes de las redes políticas y sus líderes prevalece sobre las identidades partidarias.

\section{Iztapalapa: desgaste político y alternancia partidaria}

Iztapalapa es la delegación capitalina con mayor población (casi dos millones de habitantes) y la más importante electoralmente con 1362000 empadronados y ocho distritos electorales locales. Además, recibe el presupuesto más alto en la Ciudad de México. Estas características la convierten en pieza clave, pues gobernarla consolida a cualquier partido en términos político-electorales. A partir de 2000 y hasta 2009, la facción Nueva Izquierda (NI) del PRD gobernó la delegación. Sin embargo, durante el periodo de Horacio Martínez (20062009), este redujo los apoyos delegacionales a las organizaciones, tanto porque atendió principalmente a las redes de NI, como porque intentó promover su propio grupo. Un dirigente sostenía:

eso sí le tenemos que agradecer al gobierno de Martínez, su mala administración y su forma de enfocar el gobierno y las políticas públicas que hizo (sic), las cuales promovían más su beneficio personal, olvidando totalmente lo social. Eso fue lo que nos unió a todas las corrientes. Ni el gobierno de Arce, ni el de Círigo lo habían logrado, pero Horacio (Martínez) fue la gota que derramó el vaso.?

La oposición fue estimulada por el intento de NI de que Silvia Oliva, esposa de Arce, fuera la siguiente jefa delegacional. En consecuencia, se formó una coalición de organizaciones asociada a la facción perredista Izquierda Unida (IU) liderada por Alejandro Encinas y en estrecha relación con el jefe de Gobierno, Marcelo Ebrard, quien instaló varias mesas de trabajo donde las diferentes facciones y las organizaciones de Iztapalapa aliadas a cada una de ellas negociaron candidaturas, puestos en la administración delegacional y gasto social. Un entrevistado

8 Como se amplía más adelante, la aspirante en Iztapalapa fue postulada de modo informal por el PT, ya que, si ganaba, el candidato formal renunciaría en favor de ella.

$9 \quad$ Entrevista con diputada local, 5 de junio de 2012. 
afirmó: "para negociar con eficacia, uno llega a esas mesas con todo el trabajo territorial que lo respalda, el trabajo político acumulado; sobre todo, aquel que reditúa electoralmente. Ese es el más importante en esos momentos" ${ }^{10}$ Clara Brugada fue escogida como precandidata porque "era la mejor posicionada. Debemos reconocer que ella tenía buen trabajo político, pero también tuvo mucho que ver el apoyo que le dio en ese entonces López Obrador. Este la propuso y en las negociaciones internas la respaldó”. ${ }^{11}$

Aunque una cuestión fueron los acuerdos entre diferentes organizaciones y otra, las elecciones internas en el PRD. En ellas Brugada obtuvo tres mil votos más que la precandidata de NI, pero la contienda se judicializó disputándose primero en el Tribunal Electoral del Distrito Federal (TEDF), el cual favoreció a Brugada y, posteriormente, en el Tribunal Electoral del Poder Judicial de la Federación (TEPJF) que, a dos semanas de los comicios, resolvió en beneficio de Oliva. Ante la cercanía de la elección, el Instituto Electoral del Distrito Federal (IEDF) informó que no podría reemplazar las boletas electorales para ajustarlas a la decisión del Tribunal. En ese contexto, López Obrador exhortó a los asistentes a realizar un mitin —al que asistieron Rafael Acosta, alias Juanito, y Clara Brugada - y a votar por el candidato del PT, quien públicamente aceptó renunciar a favor de ella en caso de que triunfara en las elecciones. ${ }^{12}$ Asimismo, se acordó que López Obrador celebrara diversos mítines explicando a los electores las razones para sufragar por Juanito, y que se debía votar por el PRD para diputados locales —en su mayoría líderes de las organizaciones más influyentes de la delegación - . De esta forma, se propuso al electorado de Iztapalapa sufragar mediante un voto diferenciado. Sin embargo, una entrevistada comenta:

Si pones atención encontrarás que Andrés llama a votar por el PT, mientras que nosotros tuvimos que hacer la chamba del voto diferenciado. Lo mismo sucede con Brugada: (Alejandro) Encinas me habló y me dijo "hay que meter el acelerador porque Clara (Brugada) está llamando a votar por el PT". Ahí fue cuando nos preocupamos y nos dimos cuenta que todo estaba tapizado de rojo (propaganda del PT) y solo se promovía el voto para el PT. Sin embargo, logramos elaborar nuestra estrategia y nuestros equipos explicaron a la gente cómo tenían que votar. ${ }^{13}$

10 Entrevista con el dirigente de organización de Iztapalapa, 6 de junio de 2012.

11 Entrevista con un líder del Frente Popular Francisco Villa (FPFv), 25 de junio de 2013.

12 De las entrevistas realizadas se desprende que Rafael Acosta no tenía trabajo político en Iztapalapa ni tampoco un grupo u organización que lo apoyara. Ya había perdido las elecciones internas del PRD, por lo que el PT le propuso que fuera el candidato por ese partido, lo que aceptó al tiempo que renunciaba al PRD.

13 Entrevista con diputada local por distrito de Iztapalapa, 15 de marzo de 2013. 


\section{Redes político-clientelares, facciones políticas y distritos locales}

Una encuesta de mediados de junio publicada en Milenio Diario ${ }^{14}$ indicaba que el PT contaba con $13.7 \%$ de preferencia electoral, mientras que el PRD, 33.2\%. No obstante, el PT obtuvo el $31.18 \%$ de los votos y una distancia electoral de $4.07 \%$ sobre el PRD. En este resultado confluyen: primero, el trabajo proselitista realizado por las redes para convencer a los iztapalapenses de votar por el PT para la jefatura delegacional; segundo, el trabajo político previo desplegado en algunas zonas de Iztapalapa por Brugada, fundamentalmente a través de la Unión Popular Revolucionaria Emiliano Zapata (UPREZ); tercero, el descontento de diversos sectores de Iztapalapa ante el deficiente desempeño del último delegado del grupo encabezado por René Arce; cuarto, la campaña de López Obrador para promover el voto por Juanito. Un exfuncionario delegacional reflexiona al respecto: "Arce y su grupo habían calculado que obtendrían 125000 votos, y esos fueron los que sacaron en la elección del 2009 (en realidad consiguen 127846 votos, según datos del IEDF). Les salieron bien las cuentas, pero lo que no estimaron fue un apoyo tan grande a la candidatura del PT, con Juanito (que obtuvo 180387 votos)". ${ }^{15}$

Para un análisis puntual de cómo las redes político-clientelares actuaron a nivel electoral votando por Brugada mediante el sufragio al PT hemos correlacionado: a) la información etnográfica sobre la influencia territorial de las redes políticas en los ocho distritos electorales locales en que se divide Iztapalapa; b) la adscripción política de los diputados locales triunfadores en esas elecciones; c) los resultados electorales de 2009 desagregados con base en clústeres, y d) los índices de desarrollo social (IDs) por sección electoral.

En este artículo solo nos referiremos a los distritos electorales locales XXVI, XXIX y XXXII, que son aquellos donde el PT logró mayor cantidad de votos para jefe delegacional y se caracterizan por presentar un IDs muy bajo, ${ }^{16}$ como se desprende del contraste entre los mapas 1 y 2 . En ellos la media de votos para el PT fue de $44.3 \%$, mientras que para el PRD fue de $22.7 \%$. El primero (xxvi) tenía importante presencia de grupos de la UPREZ, al que pertenecía Brugada, y algunos liderazgos locales vinculados con Arturo Santana, personaje que en el periodo 2006-2009 fue diputado local en ese distrito por Nueva Izquierda y posteriormente, en 2012, regresa apoyado por Ebrard. La competencia entre NI y la UPREZ explica la distribución de las secciones entre PRD y PT. Santana y

\footnotetext{
14 Encuesta realizada por el Grupo de Comunicación Estratégica, realizada el 17 de junio de 2009.

15 Entrevista con exfuncionario delegacional, 9 de agosto de 2013.

16 El procedimiento de elaboración del índice de desarrollo social se puede consultar en Boltvinik et al. (2011).
} 
sus redes votaron en 2009 por el PRD, buscando apoyar a su candidata, mientras que la UPREZ favoreció a Brugada través del voto para el PT.

Mapa 1. Iztapalapa. Votación 2009 para jefe delegacional por sección electoral

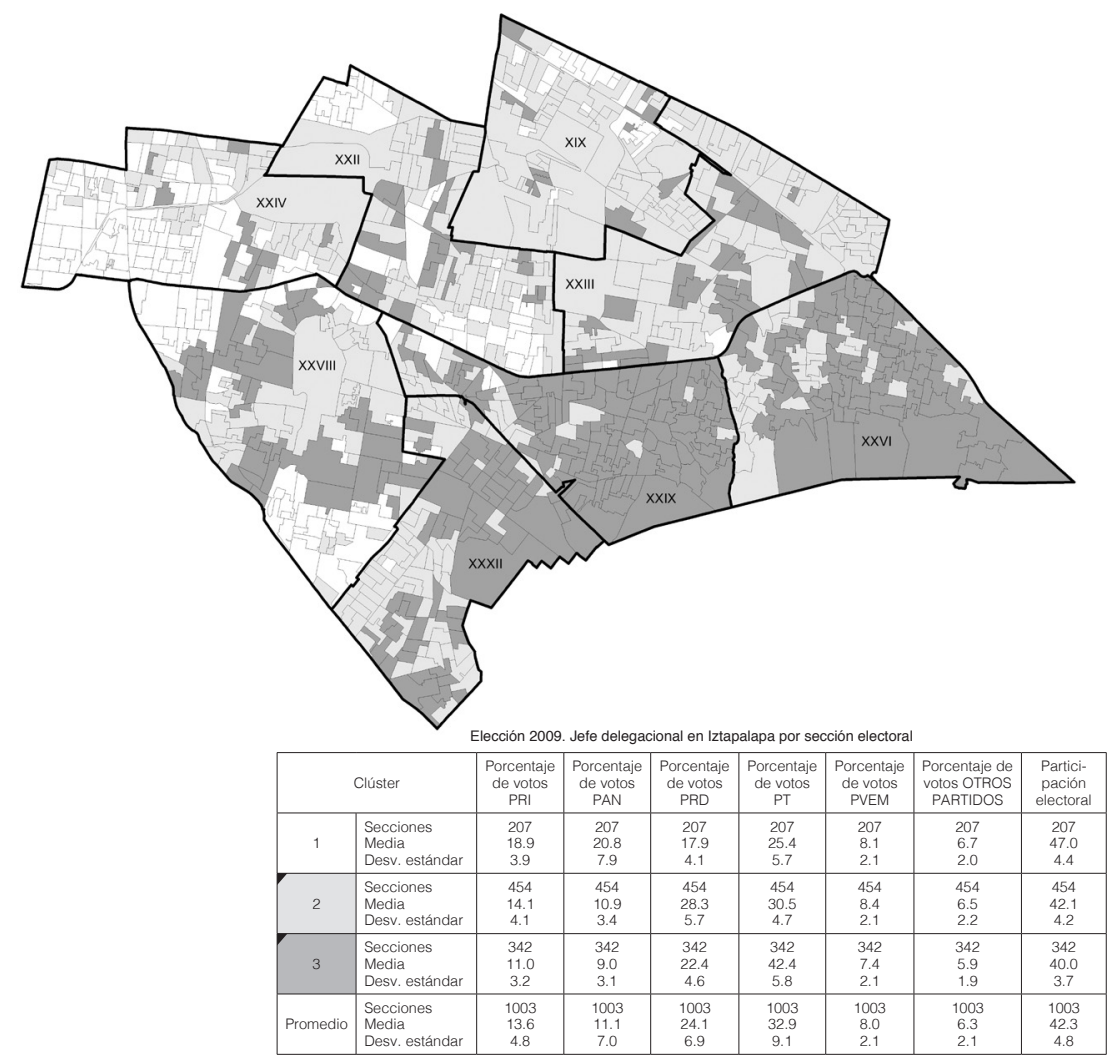

Fuente: Elaborado con datos electorales y cartografía por secciones electorales del IEDF.

Para el caso del segundo distrito (xxix), el mapa 1 indica que el voto mayoritario fue para el PT, como se desprende del clúster 2, donde obtiene 44.3\% de los votos con una desviación estándar de 5.7. Según la información etnográfica, en ese distrito electoral imperaban IDN y organizaciones como el Frente Popular Francisco Villa (FPFV), lo que inclinó la elección a favor de Brugada. En el último distrito de este grupo (XXXII), los resultados electorales muestran la disputa político-territorial abierta por el declive de la influencia de Ni, la que mantiene aproximadamente la mitad de las secciones electorales en las cuales se votó por Oliva para jefa delegacional. 


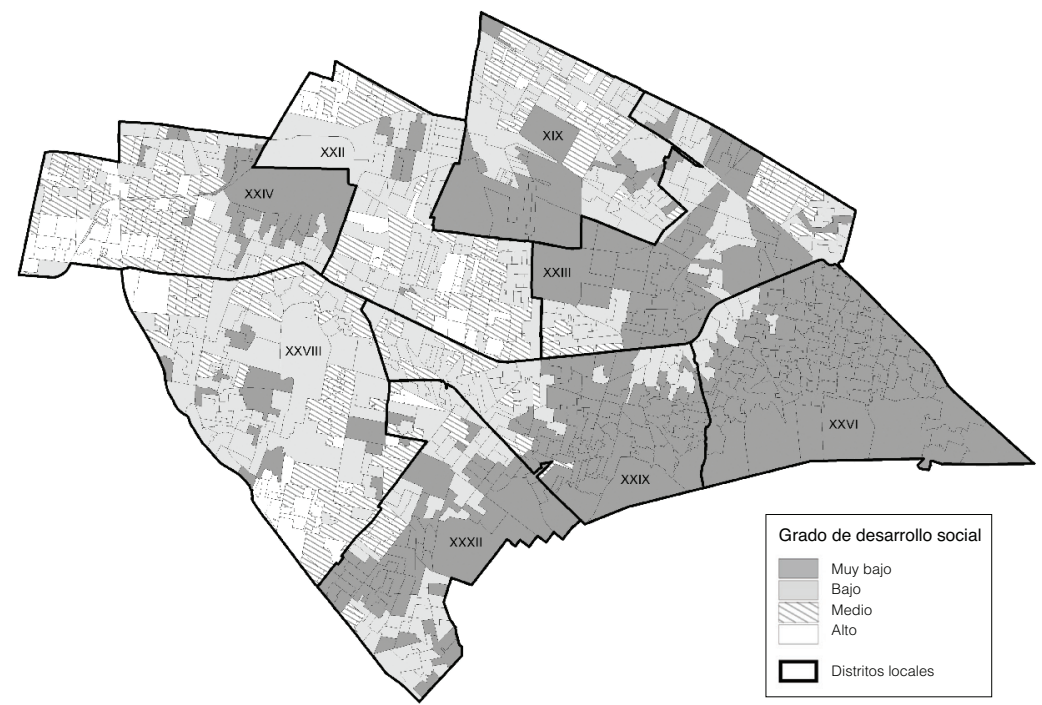

Fuente: Elaborado con información del Consejo de Evaluación del Desarrollo Social del Distrito Federal y cartografía electoral del IEDF.

En las elecciones de 2012, el PRD ganó las elecciones en Iztapalapa, lo que nuevamente dificulta mostrar la relación entre facciones, redes y comportamiento electoral. Triunfa en 999 secciones electorales, mientras que el PAN obtiene tres y el PRI solo una. Este hecho desvanece la expresión electoral de la pugna y negociación entre los dirigentes de las redes político-clientelares de Iztapalapa.

Los resultados demuestran que la estructura política que se ha configurado en la Ciudad de México no está necesariamente asociada a un partido político sino que se vincula a liderazgos territoriales que, dependiendo de sus intereses, pueden modificar su voto de un partido a otro. Lo anterior indica que la fortaleza electoral del PRD en Iztapalapa - y como veremos posteriormente, también en Cuajimalpa - está asociada a negociaciones con liderazgos locales, y no a adhesiones partidarias.

El voto mayoritario para el PRD expresa los acuerdos entre las diversas fuerzas políticas con influencia político-territorial; particularmente en cuanto a quiénes serán diputados locales, jefe delegacional y cuáles puestos ocuparán sus integrantes en la estructura administrativa de la delegación. ${ }^{17}$ El estudio etnográfico indica que la negociación final para establecer las candidaturas de 2012 a la

17 Un entrevistado afirmaba que había "hasta 300 puestos para repartir” en Iztapalapa (25 de julio de 2013). 
Jefatura Delegacional a las diputaciones locales se entabló entre IDN y Ebrard. La jefa delegacional buscaba impulsar a Varela como candidato, pero enfrentó la oposición de las diversas facciones. La negociación final se dio entre IDN y el grupo encabezado por el jefe de Gobierno. IDN priorizó entonces las candidaturas a la delegación Magdalena Contreras, y diputaciones federales y locales; mientras que Ebrard impulsaba sus candidatos en Gustavo A. Madero, Cuajimalpa, Coyoacán e Iztapalapa. Las organizaciones de esta última se inclinaron por Jesús Valencia, a propuesta de Ebrard. La comparación entre las votaciones de 2009 y de 2012 en Iztapalapa muestra que: a) los líderes de las redes con influencia político-territorial se vinculan a las diversas facciones del PRD dependiendo de las ventajas que obtienen en las negociaciones que emprenden con ellas; $b$ ) las ventajas implican ser impulsados como diputados locales o, en su caso, ocupar alguno de los puestos en la administración delegacional desde el cual pueden beneficiar a los redes que encabezan con gasto social, agilización de trámites o mejoramiento de servicios públicos; c) para los líderes de las facciones, el apoyo de estas redes les permite ampliar su influencia territorial, la cual es importante para negociar con otras facciones candidaturas y puestos administrativos en los gobiernos delegacionales y central.

La diferencia entre las elecciones de 2009 y 2012 radica, fundamentalmente, en que los acuerdos políticos entre las facciones se dificultaron ante el interés de NI por fortalecer y beneficiar a sus seguidores por encima de las demandas de otras organizaciones sociales que actúan en el territorio delegacional. Lo mismo sucedió entre Brugada y dichas organizaciones. En las entrevistas realizadas se afirma que la delegada se resistió a otorgar espacios y beneficios a los grupos que no le eran afines. También se sostiene la existencia de un constante conflicto entre el gobierno central y el delegacional, a raíz del cual el primero negoció con dichas organizaciones con el propósito de que el nuevo delegado en Iztapalapa fuese una propuesta del jefe de Gobierno.

\section{Cuajimalpa: negociaciones y fracturas entre facciones políticas}

Cuajimalpa contiene uno de los enclaves más modernos y de mayor ingreso de la Ciudad de México: la zona residencial de Santa Fe, la cual convive con colonias y pueblos de pobreza extrema. En términos electorales, la delegación pertenece al distrito local XxI, integrado por 135 secciones, 80 de ellas ubicadas en Álvaro Obregón y 75 en Cuajimalpa. El número de votantes es de 145593 (IEDF, 2012), equivalente a 9.3\% de los registrados en Iztapalapa.

Por sus características sociodemográficas, Cuajimalpa opera políticamente a nivel de colonias y pueblos. Debido a que la elección del candidato a diputado local se comparte con la delegación Álvaro Obregón — por lo que su designa- 
ción puede escapar a los deseos de las redes políticas que actúan en ella—, la contienda política se concentra en la jefatura delegacional.

Cuajimalpa destaca por su alternancia partidaria. Desde el año 2000, el PRI se desvaneció de la escena política para convertirse en la tercera fuerza electoral y la querella política quedó establecida entre el PAN y el PRD. El primero ha gobernado en 2000-2003 y 2009-2012; mientras que el segundo, en los trienios 2003-2006 y 2006-2009. Pero en las elecciones de 2012, la coalición PRI-PVEM ganó la delegación proponiendo como candidato al experredista Adrián Rubalcava.

La alternancia en esta delegación ha estado vinculada con seis elementos: a) la composición sociodemográfica delegacional propicia cierto equilibrio electoral entre las zonas con índice de desarrollo social alto (que votan usualmente por el PAN) y aquellas de índice medio o bajo en barrios y colonias (que votan preferentemente por el $\mathrm{PRD}$ ); $b$ ) los cambios en la percepción sobre el desempeño del gobierno, lo que influye en las posibilidades de que el partido del delegado mantenga la administración en la siguiente elección; c) las negociaciones entre el delegado y sus principales funcionarios con las redes políticas locales; d) el éxito de las organizaciones prepartidarias y parapartidarias ${ }^{18}$ en la atención a las demandas de las zonas con mayores carencias; ${ }^{19}$ e) los acuerdos políticos entre los candidatos de los diferentes partidos con las organizaciones de la delegación, y $f$ ) la cohesión interna en los partidos políticos, particularmente en el PRD y el PAN, ya que en la historia reciente de la delegación pueden encontrarse grupos que durante los procesos electorales renuncian a su partido y se integran a otro; por ejemplo, la incorporación de un grupo priista como "ciudadanos independientes" y coordinadores de redes en apoyo al PAN en 2009, y los conflictos en IDN que propiciaron la adhesión de varias de sus redes al priismo en 2012.

La delegación se caracteriza, como lo muestra el mapa 3, por una herradura de colonias con IDS muy bajo y voto perredista alto en las últimas tres elecciones (2003-2012), un centro con IDS medio y cierta competencia entre el PAN y PRD, y una zona alta con voto históricamente panista con IDS medio y alto. El mapa no muestra al PRI, ya que su promedio electoral ha sido históricamente bajo.

18 Hemos acuñado el término redes prepartidarias para referirnos a las organizaciones formadas por algunos emprendedores políticos que las constituyen para tener presencia pública e insertarse en la política de partidos. En el caso de las parapartidarias, se trata de aquellas que han sido promovidas por los integrantes del aparato político y gubernamental para ampliar su influencia política.

19 Aquellas con más influencia política han sido las que promueven construcción de vivienda y el mejoramiento de servicios, debido al gran número de asentamientos irregulares en la delegación. 


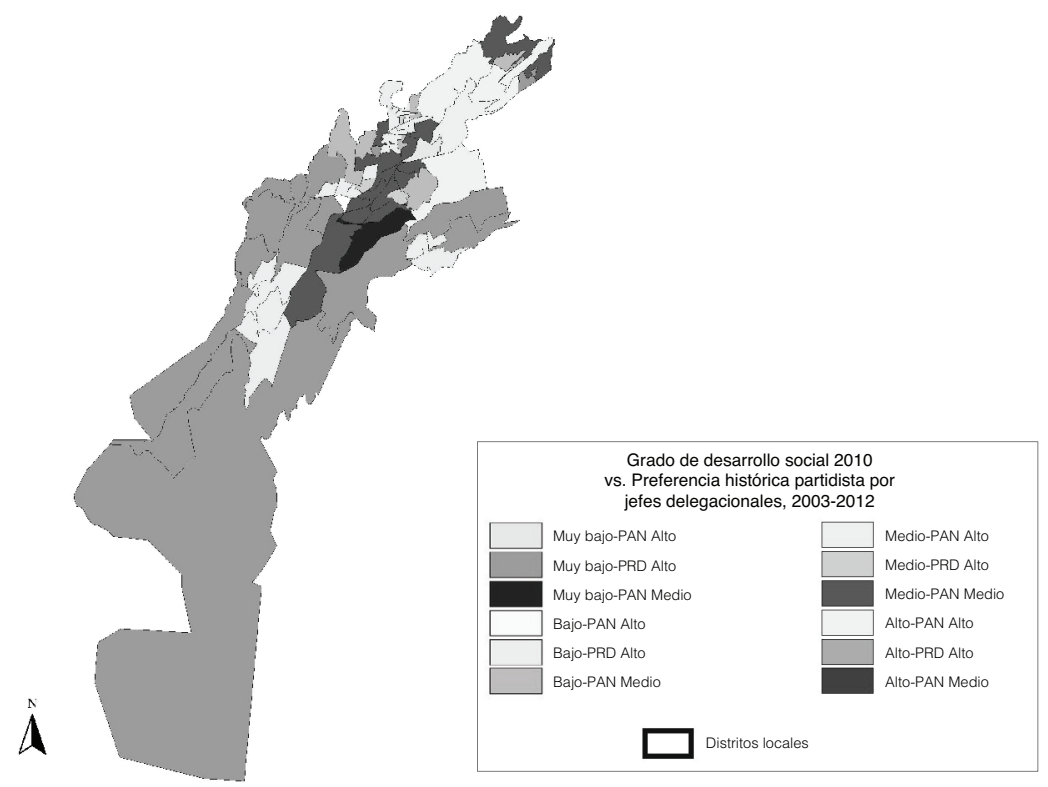

Fuente: Elaborado con información del Consejo de Evaluación del Desarrollo Social del Distrito Federal y cartografía electoral del IEDF.

\section{Organizaciones sociales y proselitismo}

En Cuajimalpa la política se liga estrechamente a la acción de las organizaciones que proporcionan atención a problemas relacionados con los servicios urbanos, buscando ampliar así el número de beneficiarios de programas sociales. También impulsan proyectos de abasto popular, faenas colectivas y trabajo comunitario. Actúan bajo la bandera de sociedad civil y son útiles para que las facciones políticas amplíen sus espacios territoriales de influencia y tengan una base de apoyo para definir candidaturas. Además, permiten a sus líderes ascender políticamente. En el ámbito de las organizaciones parapartidarias, destacan la ANTAAJ, A. C. y el Movimiento Nacional por la Esperanza (MNE). La primera fue fundada por el exdelegado del PAN, en el periodo 2009-2012, y ha sido sujeta de diversas denuncias por haber sido apoyada con recursos gubernamentales por la administración panista durante ese trienio, y haber estado encabezada por la madre del delegado en ese mismo periodo. La segunda, el MNE de René Bejarano, congrega a diversas organizaciones y movimientos urbanos dispersos en la Ciudad de México. A partir de 2009 fue encabezada en 
Cuajimalpa por Rubalcava. Sostiene que su objetivo es construir una sociedad democrática y justa a través de la satisfacción de demandas ciudadanas como el empleo, seguridad social, vivienda, becas, educación, útiles escolares y enfatiza en los derechos de los homosexuales, jóvenes, mujeres, adultos mayores y la niñez. En los hechos, quienes participaron en ella fueron, fundamentalmente, gestores de vivienda, de permisos de comercio, así como de apoyos escolares a niños y jóvenes.

No daremos una descripción de otras asociaciones que actúan a nivel de pueblos y barrios de Cuajimalpa, pero las campañas electorales en esta delegación han estado marcadas por su influencia política.

\section{"Negociación mata convocatoria": el proceso de ruptura con el PRD}

Para las elecciones de 2012, la convocatoria del PRD estableció que las candidaturas se otorgarían con base en los resultados de una encuesta de opinión, pero también a partir de los acuerdos entre las facciones partidistas. Del estudio etnográfico realizado se desprende que la selección de candidato a jefe delegacional fue resultado de negociaciones entre Bejarano y Ebrard, sin tomar en cuenta la popularidad con base en encuestas. Algunos entrevistados sostienen que Cuajimalpa era una de las tres delegaciones catalogadas como panistas, ${ }^{20}$ en las cuales se había acordado que el candidato a jefe delegacional sería elegido basándose en los resultados de las encuestas en dichas delegaciones. Siendo así, el precandidato con mejores resultados era Rubalcava. Las entrevistas también indican que, en realidad, la elección fue resultado de un intercambio: Cuajimalpa para el grupo de Ebrard y Magdalena Contreras para IDN. La encuesta fue empleada para encubrir el acuerdo entre facciones.

Rubalcava no fue incluido como posible candidato a jefe delegacional por el PRD, pero de nuestras entrevistas se desprende que se le ofreció una candidatura a la Asamblea Legislativa, lo mismo que la presidencia de una comisión "jugosa”. Todo ello si abandonaba sus expectativas a la jefatura delegacional. Sin embargo, renunció al PRD el 1 de febrero de 2012. Días después anunció su precandidatura a la delegación por el Partido Verde Ecologista de México (PVEM) en coalición con el PRI. Para justificarse, denunciaba un supuesto atentado (su automóvil, estacionado, recibe impactos de bala), la inexistencia de condiciones equitativas en el proceso y el interés de Ebrard de controlar la delegación para, afirmaba, realizar proyectos como La Mexicana, mediante el cual se pretendía

20 Aun cuando las encuestas indicaban que el PRI podía ganar la elección a jefe delegacional en 2012. 
construir 5500 viviendas en el predio denominado así, en Santa Fe. ${ }^{21}$ Este proceso representó la segunda escisión de IDN en la delegación.

La salida de Rubalcava y la integración de una facción de IDN bajo ese liderazgo al PRI-PVEM reconfiguró la estructura de poder político-territorial de los partidos, facciones y grupos de interés de Cuajimalpa, y de las relaciones entre las redes políticas construidas en torno a estos. Por ejemplo, la realineación de los liderazgos afines a Rubalcava incluyó los pueblos de San Lorenzo Acopilco y San Mateo Tlaltenango, y las colonias Ébano, El Yaqui y Las Galicias.

\section{“Aquí, allá, ¡Adrián les va a ganar!”: el triunfo del PRI-PVEM}

La campaña electoral en Cuajimalpa fue particularmente competitiva debido a la disputa por las redes políticas y el control de los territorios entre los candidatos del PRD-PT-MC y del PRI-PVEM, al cual se fueron sumando (y restando) liderazgos, comités ciudadanos y equipos políticos hasta el último minuto de la jornada electoral. Los líderes afines al PAN optaron por oscilar entre el PRI-PVEM y ese partido. Una semana colaboraban en uno y movilizaban a sus redes para demostrar su poder de convocatoria ante el aspirante; la semana siguiente lo hacían para el equipo contrario. Algunos líderes, vaticinando el resultado de la jornada electoral decidieron apoyar, en el último minuto, al candidato del PRI-PVEM. Lo anterior confirma que las redes y quienes las encabezan son pragmáticos, flexibles y propensos a cambiar la orientación de su apoyo político.

En términos similares a Iztapalapa, el comportamiento electoral en Cuajimalpa es consecuencia de la interinfluencia de varios elementos: primero, la vinculación entre redes políticas locales y funcionarios como sucedió con Rubalcava que había sido director de Jurídico y Gobierno en Cuajimalpa (20062008) y director general de Fomento Económico en el gobierno de la Ciudad de México (2009-2012); ${ }^{22}$ segundo, la reacción ciudadana adversa por el deficiente desempeńo del delegado panista en el trienio 2009-2012; tercero, la negociación entre facciones (en este caso, el líder de la IDN y el jefe de Gobierno) para elegir candidato; cuarto, la disminución de votos por el PAN —a pesar de su campaña permanente y la consolidación de clientelas en la delegación-, debido al descrédito de la administración federal, los conflictos intrapartidarios por las candidaturas en la Ciudad de México, y, como en Cuajimalpa, por la judicialización de la pugna entre sus dos principales aspirantes.

21 Discurso del candidato en reunión con vecinos en junio de 2012.

22 Desde donde otorgó apoyo para la obtención de permisos para instalar cocinas económicas y tiendas de abarrotes, entre otros. 
El excandidato perredista triunfó en los comicios con base en el proselitismo realizado como funcionario tanto delegacional como del gobierno central, así como por las negociaciones entabladas con las redes político-territoriales ubicadas en la delegación. ${ }^{23}$ Además, el propio Rubalcava fue tejiendo y consolidando sus redes antes de las elecciones de 2012, particularmente en San Lorenzo Acopilco, y de ahí se fue extendiendo a otros pueblos y colonias que habían votado en las elecciones anteriores por el PAN, como Primero de Mayo, Agua Bendita, Cruz Blanca, San Pedro Cuajimalpa, El Tianguillo, Xalpa, Zentlapatl y diversas secciones de San Mateo Tlaltenango y de una zona catalogada cartográficamente como federal. Diversos barrios y pueblos que en 2009 se inclinaron por el PRD, votaron por el PRI en 2012. Entre ellos destacan Cola de Pato, La Pila, Las Lajas, Las Maromas y secciones disputadas con el PRD en San Mateo Tlaltenango, Xalpa y la zona federal. En todos ellos, en 2012, el PRI obtuvo el 40.5\%, el PAN, 13.1\% y el PRD 33.2\% de la votación.

Mapa 4. Cuajimalpa. Votación para jefe delegacional por sección electoral y colonia, 2012

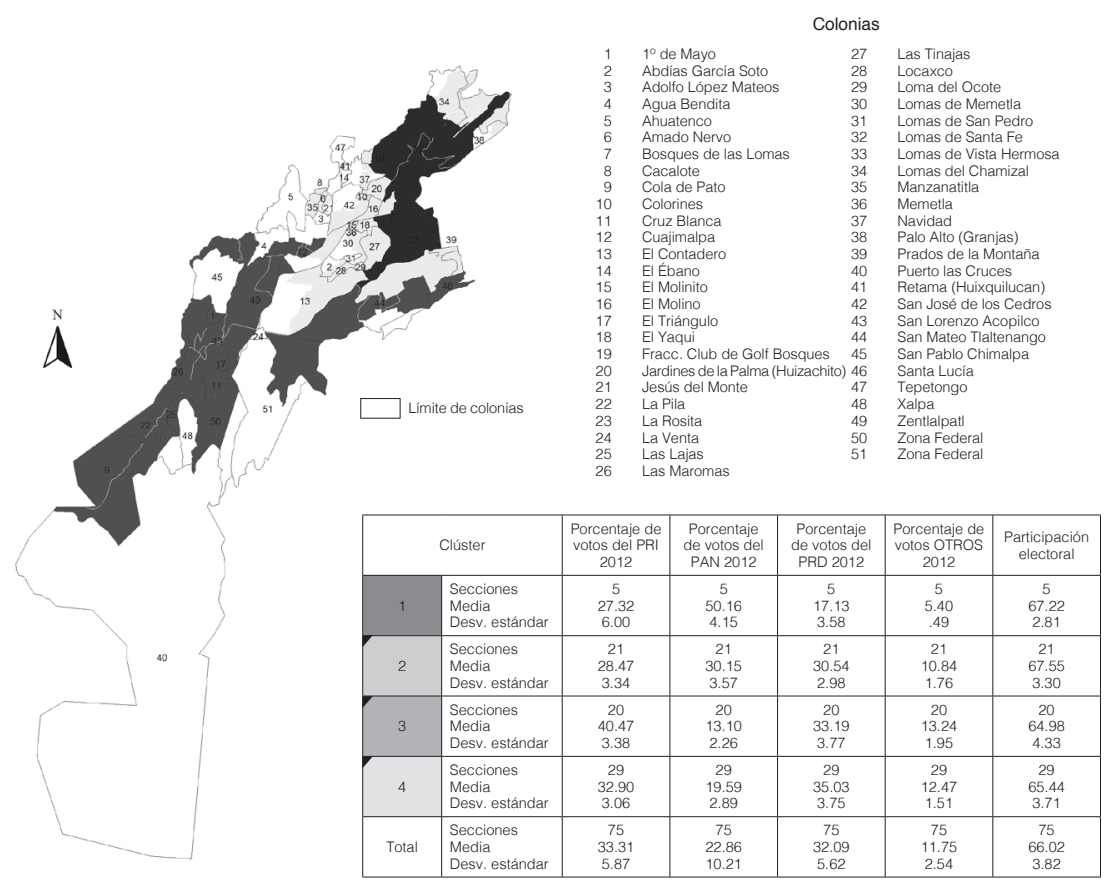

Fuente: Elaborado con datos electorales y cartografía por secciones electorales del IEDF.

23 Recuérdese que Cuajimalpa forma parte de un solo distrito electoral local en conjunto con una porción de la delegación Álvaro Obregón, por lo que realizamos un análisis por colonias y no por distritos electorales. 


\section{A manera de conclusión. Redes y prácticas políticas}

Hemos seguido una estrategia teórico-metodológica sustentada en un enfoque procesual (Sztompka, 1991) para profundizar en las relaciones políticas en contextos locales, estudiando los vínculos entablados entre los gobiernos central y delegacionales, facciones políticas y redes político-territoriales, buscando determinar cómo se ejerce la dominación (Simmel, 2009 [1908]); es decir, el contenido de las prácticas mediante las cuales se reproduce y fortalece la estructura política en la Ciudad de México.

La estructura política que caracteriza a la Ciudad de México se despliega territorialmente mediante dos procesos: el primero, la construcción de acuerdos políticos entre dirigentes de facciones partidarias y quienes encabezan las redes clientelares en los espacios locales. Las relaciones establecidas entre ambos son dúctiles, débiles, coyunturales y dependen de negociaciones que estipulan los beneficios que, en el futuro, obtendrán dichas redes y sus dirigentes; la entrega de apoyos directos expresados en gasto social (becas escolares, ayudas para adultos mayores y madres solteras, por ejemplo), gestiones para el mejoramiento de los servicios, así como el impulso a la economía (créditos y permisos para ejercer el comercio), entre otros. Las alianzas generadas son pragmáticas y responden a las aspiraciones políticas de los líderes de las redes y las expectativas de sus integrantes.

El segundo proceso territorial es la movilización de las redes para consumar los acuerdos. La etnografía de los procesos políticos abordados indican que el direccionamiento del voto no se restringe a quienes integran las redes políticas; existe un efecto multiplicador en su proselitismo como resultado de los vínculos de parentesco y por rituales (compadrazgo), así como de la influencia vecinal sustentada en la identidad generada por compartir un territorio común, lo cual irradia el comportamiento electoral de las redes hacia grupos más extensos. En este sentido, esas redes no necesariamente tienen que ser muy amplias para ser electoralmente eficaces, sino mostrar capacidad para, mediante la interacción cotidiana, canalizar las percepciones de familiares y vecinos.

En Cuajimalpa, la eficacia electoral de las redes político-clientelares reside, en gran parte, en los estrechos vínculos identitarios existentes en pueblos y barrios, los cuales propician que el proselitismo electoral de dichas redes sea más efectivo, porque la credibilidad se incrementa en la medida en que se comparten cultura y territorio. Lo anterior se refleja en los resultados electorales de los mapas que hemos presentado. El diseño cartográfico de los clústeres muestra divisiones por colonia o barrio, pero al analizarlos con base en las secciones electorales se observa que, salvo marcadas excepciones en Cuajimalpa, Chimalpa y Zentlapatl, las colonias y pueblos se comportan de 
forma corporativa y las secciones que contienen se integran bajo una misma preferencia electoral.

Tanto en Iztapalapa como en Cuajimalpa votar por uno u otro partido fue percibido por muchos de los integrantes de las organizaciones como un "cambio de color" (más que de ideología o identidad política) para conseguir el resultado deseado en términos de atención gubernamental o ascenso político de sus líderes; aunque en el caso del PRD al PRI, se requirieron mayores justificaciones.

La consolidación del PRD es producto tanto de la integración de múltiples redes con identificaciones político-clientelares particulares, matizadas por lazos morales de reciprocidad, interés mutuo y pragmatismo, todo ello condensado en sus líderes, como de la tradición opositora sobre cuyas características nos hemos detenido en las primeras páginas de este artículo. Su fortaleza está parcialmente sujeta a las aspiraciones de quienes buscan consolidar espacios locales de influencia política. Pero dichas aspiraciones pueden transmutarse, como se muestra en los casos presentados, en votos a un partido distinto.

La estructura política que prevalece actualmente en la Ciudad de México es resultado de: a) la configuración de una entidad con una cultura de oposición política; b) la permanencia del PRD como partido predominante en el gobierno a partir de 2003, donde esa cultura se combina con el consenso logrado a partir de avances en política social y urbana; $c$ ) la transformación paulatina de los líderes perredistas en élite política; $d$ ) la conformación de facciones al aplicar las políticas públicas con base en un enfoque clientelar que desplaza la participación ciudadana y la exigibilidad de derechos reduciéndolas a gasto social focalizado (Álvarez, 2006) y subordinación política (Dagnino, 2010); e) el fortalecimiento de redes políticas como las observadas en Iztapalapa y Cuajimalpa, cuya acción propicia un patrón de dominio político-territorial sustentado en facciones partidarias que luchan por el predominio político-electoral; $f$ ) condiciones socioeconómicas adversas y debilidad política de las mayorías que propician relaciones clientelares.

Finalmente, si bien se ha consolidado una nueva estructura política en la Ciudad de México asociada a una élite política formada en los últimos quince años, al estar sustentada en relaciones de asociación entre facciones partidarias que rivalizan entre ellas y una pléyade de organizaciones cuyas adhesiones están condicionadas a ventajas coyunturales, su estabilidad es volátil. En estas circunstancias, las posibilidades de que el PRD pierda influencia en los espacios locales y, con ello, delegaciones y diputaciones, depende de la fortaleza de sus alianzas y, a nivel más general, en los niveles de aprobación de jefes delegacionales y jefe de Gobierno. En las entrevistas sobre el tema realizadas al principio de 2015, se ha encontrado que los operadores políticos de ese partido han mantenido sus alianzas con las organizaciones urbanas, lo que acota las posibilidades 
de otros partidos, pero en términos generales, más allá de las redes políticas, los márgenes de preferencia electoral de los cuales gozaba entre los habitantes de la Ciudad de México están disminuyendo ${ }^{24}$ — mientras que tanto el Movimiento de Regeneración Nacional (Morena) como el PRI ascienden en algunas delegaciones políticas-, como producto de la lucha entre sus facciones, y su desempeño partidario y gubernamental.

\section{Referencias}

Alvarado Mendoza, A. (2012). El tamaño del infierno. Un estudio sobre la criminalidad en la Zona Metropolitana de la Ciudad de México. México: El Colegio de México.

Álvarez, L. (2006). Participación ciudadana y construcción de ciudadanía en la Ciudad de México. En Elecciones y ciudadanía en el Distrito Federal (pp.51-86). México: Instituto Electoral del Distrito Federal.

Álvarez, L. (2013 [1998]). Distrito Federal: sociedad, economía, politica y cultura, México: CEIICHUNAM.

Auyero, J. \& Lauren, J. (2007). Introduction: Politics under the Ethnographic Microscope. En Lauren, J. \& Auyero, J. New Perspectives in Political Ethnography (pp.1-13 ). Nueva York: Springer.

Baczko, B. (1991). Los imaginarios sociales. Memorias y esperanzas colectivas. Buenos Aires: Nueva Visión.

Balbi, F. A. \& Boivin, M. (2008). La perspectiva etnográfica en los estudios sobre política, Estado y gobierno. Cuadernos de Antropología Social, (27), 7-17.

Becerra, P. (2005), De la posrevolución a nuestros días, 1923-2003. En Emmerich, G. (Coord.). Las elecciones en la ciudad de México (1376-2005) (pp. 291-357). México: Iedf/uAm.

Belloni, F. P. \& Beller, D. C. (1996). The Study of Party Factions as Competitive Political Organizations. The Western Political Quarterly, 9(4), 531-549.

Boltvinik, J. et al. (2011). Indice de desarrollo social de las unidades territoriales del Distrito Federal delegación, colonia y manzana. México: Consejo de Evaluación del Desarrollo Social del Distrito Federal.

24 Para diciembre de 2014, Morena ha pasado del 14\% de preferencia electoral en julio de ese año a 26\%, mientras que el PRD ha bajado de 29 a 22\% (Reforma, 2014). 
Bruhn, K. (2012). El PRD y los movimientos populares en el Distrito Federal. En CadenaRoa, J. \& López Leyva, M. A. El PRD: orígenes, itinerario y retos (pp. 133-154). México: IIS-UNAM/CEIICH-UNAM.

Creswell, J. (2007). Qualitative Inquiry and Research Design: Choosing Among Five Approaches. California: Sage Publications.

Dagnino, E. (2010). La construcción democrática en Brasil: la participación de la sociedad civil y sus dilemas. Vanguardia, (36).

Emmerich, G. (2005). Introducción. En Emmerich, G. (Coord.). Las elecciones en la Ciudad de México (1376-2005) (pp. 15-26). México: IEDF/UAM.

Frutos, M. (2002). La participación del movimiento urbano popular en el proceso de cambio politico en el Distrito Federal (1986-1997). Tesis de Maestría en Ciencias Sociales. Facultad Latinoamericana de Ciencias Sociales, Sede México. México.

Geertz, C. (1973). La interpretación de las culturas. Barcelona: Gedisa.

Gómez-Tagle, S. (2000). Nuevas formaciones políticas en el Distrito Federal. En Gómez-Tagle, S. \& Valdés, M. E. (eds.). La geografía del poder y las elecciones en México (pp. 39-94). México: Plaza y Valdés.

Reforma. (2014, 17 de diciembre). Encuesta Reforma Elecciones 2015. Reforma (Primera plana).

Salas-Porras A. \& Luna, M. (2012). Introducción: ¿quién gobierna América del Norte? En SalasPorras, A. \& Luna, M. (Coords.). ¿Quién gobierna América del Norte?: élites, redes y organizaciones. México: UNAM.

Simmel, G. (2009 [1908]). Inquiries into The Construction of Social Forms. Países Bajos: Brill.

Sztompka, P. (1991). Society in Action: The Theory of Social Becoming. Chicago: University of Chicago Press.

Vaughan, M. K. (2001). Transnational Processes and the Rise and Fall of the Mexican Cultural State. En Joseph, G. et al. (Eds.). Fragments of a Golden Age: The Politics of Cultures in Mexico Since 1940 (pp. 471-487). Durham: Duke University Press.

Recibido el 31 de enero de 2015. Aceptado el 27 de septiembre de 2016. 